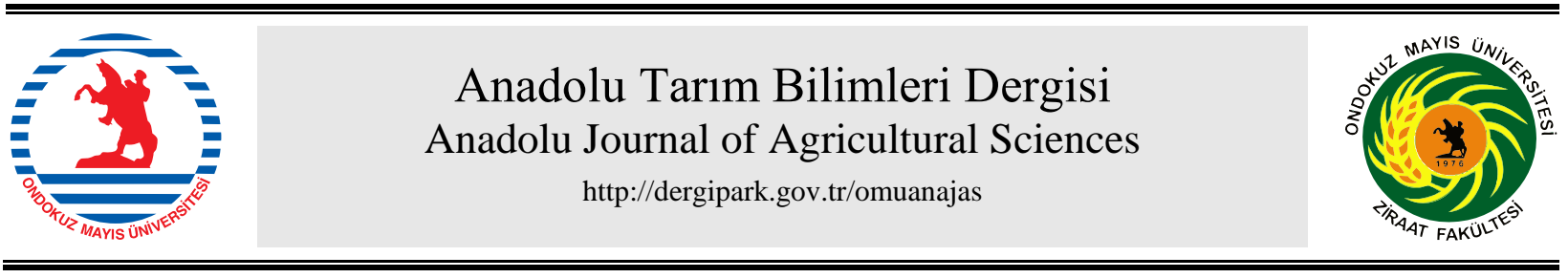

Araştırma/Research

Anadolu Tarım Bilim. Derg./Anadolu J Agr Sci, 34 (2019) ISSN: 1308-8750 (Print) 1308-8769 (Online) doi: 10.7161/omuanajas.418694

\title{
Kuru tarımda farklı toprak işleme sistemleri ile buğday üretiminin enerji kullanım etkinliği analizi
}

\author{
Ebubekir Altuntaşa*, Osman Nuri Bulut ${ }^{\mathrm{b}}$, Engin Özgöz ${ }^{\mathrm{a}}$ \\ ${ }^{a}$ Gaziosmanpaşa Üniversitesi Ziraat Fakültesi Biyosistem Mühendisliği Bölümü, Tokat \\ ${ }^{\mathrm{b}}$ Tarım ve Orman Müdürlüğü, Sivas. \\ ${ }^{* *}$ Sorumlu yazar/corresponding author: ebubekir.altuntas@gop.edu.tr
}

Geliş/Received 26/04/2018～Kabul/Accepted 20/11/2018

\begin{abstract}
ÖZET
Bu çalışmada, Sivas ilinde kuru tarım şartlarında buğday tarımında 4 farklı toprak işleme [1) Doğrudan ekim (DE) (Doğrudan ekim makinesi), 2) Koruyucu toprak işleme (KT) (Çizel+diskli tırmık+hububat ekim makinesi), 3) Azaltılmış toprak işleme (AT) (Rotovatör+hububat ekim makinesi) ve 4) Geleneksel toprak işleme (GT) (Kulaklı pulluk+diskli tırmık+hububat ekim makinesi)] sistemlerinin enerji kullanım etkinliği incelenmiştir. Denemelerde tohumluk olarak Bezostaja-1 kışlık buğday çeşidi kullanılmıştır. Enerji parametreleri olarak enerji oranı, özgül enerji, enerji verimliliği, net enerji ve enerji kârlılığı göz önüne alınmıştır. Buğday üretiminde incelenen toprak işleme sistemlerinin hepsinde toplam girdi enerjileri içerisinde en yüksek payı kimyasal gübre enerjisi alırken, bunu tohum enerjisi ve yakıt+yă̆ enerjisi takip etmiştir. Araştırma sonuçlarına göre; en yüksek ve en düşük enerji oranı değerleri sırasıyla AT (4.87) ve GT (4.53) sistemlerinde elde edilirken, en yüksek özgül enerji değeri GT (3.25 $\left.\mathrm{MJ} \mathrm{kg}^{-1}\right)$ ve en düşük özgül enerji değeri ise AT (3.02 MJ kg-1) sisteminde elde edilmiştir. Toprak işleme sistemleri net enerji değeri bakımından GT $>$ AT $>$ KT $>$ DE şeklinde sıralanmıştır. Enerji oranı, özgül enerji, enerji verimliliği ve enerji kârlılığı değerlerine göre Sivas ilinde, buğday tarımında, geleneksel toprak işleme yöntemi yerine doğrudan ekim, koruyucu toprak işleme ve azaltılmış toprak işleme sistemlerinin kullanılabilir olduğu sonucuna varılmıştır.
\end{abstract}

Energy use efficiency analysis of wheat production with different soil tillage systems in dry agriculture

\section{ABSTRACT}

In this study, the four different tillage systems (1 (no-tillage (DE) (no till planter); 2) conservational tillage system (KT) (chisel+ disc harrow+planting); 3) reduced soil tillage system (RT) (rotovator+planting); 4) conventional soil tillage system (GT) (mouldboard plough+ disc harrow+planting)] were compared in terms of energy use efficiency under dry farming condition for Bezostaja-1 wheat cultivar in Sivas province. Energy ratio, specific energy, energy productivity, net energy and energy profitability were taken into consideration as energy parameters. The highest energy input was obtained as fertilizer, seed, and fuel +oil energies in all tillage systems for wheat farming, respectively. According to results; the highest and lowest energy values are obtained in AT (4.87) and GT (4.53) systems respectively, while the highest specific energy value was obtained in the GT (3.25 $\left.\mathrm{MJ} \mathrm{kg}^{-1}\right)$ and the lowest specific energy value was obtained in the AT (3.02) $\mathrm{MJ} \mathrm{kg}^{-1}$ ) system. Soil tillage systems are listed in terms of net energy value $(\mathrm{MJ})$ as $\mathrm{GT}>\mathrm{AT}>\mathrm{KT}>\mathrm{DE}$ from high value to low value depending on net energy. In Sivas province, no-till, reduced tillage and conservational tillage systems could be used instead of the traditional tillage method in wheat farming according to the energy ratio, specific energy, energy efficiency and energy profitability values.

Anahtar Sözcükler: Koruyucu toprak işleme Doğrudan ekim, Enerji oranı Net enerji

\section{Giriș}

Son yıllarda gerek dünyada ve gerekse ülkemizde doğal ekosistemi ve özellikle de daha hassas olan agro ekosistemi korumak için temel amacın toprağı korumak ve toprak verimliliğini artırmak olduğu sürdürülebilir tarım uygulamaları gündeme gelmiştir. Sürdürülebilir tarım; toprak, su ve hava gibi çevresel faktörleri dikkate alıp, insan, bitki ve hayvan sağlığını koruyarak üretim yapma düşüncesidir (Çarman ve ark., 2014). 
Sürdürülebilir tarımsal üretim için temel gereksinimlerden birisi olan enerji kaynaklarının etkin kullanılması sağlandığında; fosil kaynaklar korunmakta ve hava kirliliğinin azalması mümkün olabilmektedir. Enerji etkinliğini artırmak için üretim verimini artıracak veya verimi etkilemeden enerji girdisini koruyacak adımların atılması gerekir (Singh et al., 2004). Bu yüzden, sürdürülebilir tarımsal üretim için enerji tasarrufu hayati bir konudur (Uhlin, 1998; MousaviAvval ve ark., 2012).

Enerji girdisindeki artışla verim artmaktadır. Fakat enerji girdisindeki aşırı artış, bazı ekonomik zararlara neden olabilmektedir (Alikhani ve Nezhad, 2004). Enerji etkinliği için ya verimin artırılması ya da girdilerin azaltılması gerekmektedir. Verimin arttırılması belirli sınırlar içerisinde sağlanabilir. Fakat enerji kullanım etkinliği, girdilerin bilinçli bir şekilde uygulanması ile azaltılabileceği için (Gözübüyük ve ark., 2012) üretimde kullanılan sistemlerin enerji dengesini hesaplamak oldukça önemlidir (Alikhani ve Nezhad, 2004).

Geliştirilmiş tarımsal üretim için doğru miktarda enerjiyi yeterli miktarda tedarik etmek, etkin ve verimli kullanmak gereklidir (Mohammadi ve Omid, 2010). Yakıt, elektrik, tohum, gübre ve kimyasallar gibi girdiler modern tarımın üretim sistemindeki enerjiyi önemli bir şekilde tüketen kaynaklardır (Hatirli ve ark., 2006). Tarımsal üretimde en büyük enerji ve iş gücü tüketicisi, toprak işlemedir. Birincil toprak işleme uygulamaları, ekimden önce tüketilen toplam enerjinin \% 75'ine ihtiyaç duymaktadır (Pelizzi ve ark., 1988). Bu yüzden, uygun toprak işleme sisteminin seçimi; sistemlerin çevre kirliliğini kontrolünü ve enerji korumasının belirlenmesini kapsamaktadır (Tabatabaeefar ve ark., 2009)

Borin ve ark. (1997) tarladaki enerjinin \% 30'unun toprak işlemede tüketildiğini; Bonari ve ark. (1995), toprak işlemeyi azaltmanın ürün veriminde önemli bir farklılık olmadan geleneksel toprak işlemeye göre yakıt tüketimini \% 55 azalttığını; Chaplin ve ark. (1988), doğrudan ekim ve azaltılmış toprak işleme sistemleriyle çeki enerjisi kullanımının sırasıyla \% 84 ve \% 54 azaldığını rapor etmişlerdir (Tabatabaeefar ve ark., 2009).

Karaağaç ve ark. (2012), Çukurova bölgesinde buğday tarımında düze ekim ve sirta ekim yöntemlerinin enerji bilançolarını belirledikleri çalışmalarında, enerji oranının düze ekimde 6.63 ve sırta ekimde 5.29 olduğunu ifade etmişlerdir. Tabatabaeefer ve ark. (2009), buğday üretiminde farklı toprak işleme sistemlerinin enerji etkinliğini karşılaştırdıkları çalışmalarında geleneksel uygulama ve doğrudan ekim uygulaması için enerji oranını sırasıyla 3.65 ile 4.87 olarak belirlemişlerdir. Çarman ve ark. (2014), Orta Anadolu koşullarında 5 farklı toprak işleme sisteminin buğday üretimindeki enerji bilançolarını belirledikleri çalışmalarında, en yüksek çıktı/girdi oranına sahip olan doğrudan ekim uygulamasının daha kârlı bir üretim tekniği olduğunu ifade etmişlerdir. Orta Anadolu koşullarında yapılan başka bir çalışmada da buna benzer sonuçlara ulaşılmış ve buğday üretiminde doğrudan ekim uygulamalarında çıktı/girdi oranı 2.81 olarak belirlenmiştir (Marakoğlu ve Çarman, 2010). Kusotic ve ark. (2005), kışlık buğday için geleneksel toprak işlemede $315.32 \mathrm{MJ} \mathrm{Mg}^{-1}$ harcandığını ve koruyucu toprak işlemede $192.38 \mathrm{MJ} \mathrm{Mg}^{-1}$ harcama ile \% 39 tasarruf yapılırken, doğrudan ekim sisteminde ise $47.14 \mathrm{MJ} \mathrm{Mg}^{-1}$ ile \% 85.1 tasarruf sağlandığını belirtmişlerdir (Tabatabaeefar ve ark., 2009).

Golaszewski ve ark. (2014), Avrupa' da farklı iklim bölgelerindeki buğday üretiminin enerji etkinliği karşılaştırmak ve seçilen enerji koruma önlemleri ile ortaya çıkan enerji, ekonomi ve çevresel faydaları değerlendirmişlerdir. İklim ve ülkeye bağlı olarak farklı enerji koruma önlemlerini öngörmüşlerdir. Dolaylı ve doğrudan enerji girdilerinin büyük ölçüde coğrafi konum ve iklim bölgelerine özgü olduğunu, iklim bölgelerinde verimdeki artışı toplam enerji girdisindeki artışa paralel olduğunu ifade etmişlerdir. Belirli bir tarımsal üretim sisteminde enerji tüketimi ve enerji tasarrufu potansiyelinin, belirli coğrafi alanlarda ve iklim bölgelerinde farklılaştı̆̆ını belirtmişlerdir.

Çalışmanın yapıldığ Sivas ili, $27202 \mathrm{~km}^{2}$ 'lik alanı ile Türkiye'nin en büyük yüzölçümüne sahip ikinci ilidir. Sivas ili tarım alanlarının 2519043 hektarı rüzgâr ve su erozyonu etkisinde olduğu için, sürdürülebilir bir tarımsal üretim sistemine geçilmesi, toprak ve su kaynakların koruyan ve erozyon tehdidini azaltan toprak işleme sistemleri uygulanmalıdır (Anonim, 2014a). Sivas ili bitkisel üretiminde hububat ağırlıklı bir üretim yapılmakta olup 2017 yılında toplam tarım alanlarının \% 33.79' unda buğday tarımı yapılmıştır (TÜİK, 2017).

Ana ürün olarak kuru tarım şartlarında buğday tarımının yapıldığı Sivas ilinde sürdürülebilir bir tarımsal üretimin sağlanması için, verimi de dikkate alarak toprak, su ve çevreyi koruyan toprak işleme sistemlerinin belirlenmesi gerekmektedir. Bu çalışmada, Bulut (2015) tarafından toprak işleme sistemlerinin toprak özellikleri, buğdayın bitki çıkış özellikleri ve verim özellikleri bakımından karşılaştırmasının yapıldığı çalışmada kullanılan sistemler enerji etkinliği açısından değerlendirilmiştir.

\section{Materyal ve Yöntem}

Çalışmada sistemlerin enerji etkinliğini belirlemede, Bulut (2015) tarafindan elde edilen veriler kullanılmıştır. Bulut (2015), Sivas ilinde kuru şartlarda yürüttüğü çalışmada buğday tarımında farklı toprak işleme sistemlerini; toprak özellikleri, tarla filiz çıkışı ve verim üzerine etkileri yönünden karşılaştırmıştır. Çalışma 2012-2013 üretim sezonunda, rakımı yaklaşık $1260 \mathrm{~m}$ olan düz-düze yakın eğimli (\% 0-2) bir çiftçi arazisinde yürütülmüştür. Deneme alanına ait buğday ekiminden hasadına kadar geçen süre içerisindeki yağış miktarları Çizelge 1 ve deneme alanı topraklarının bazı toprak özellikleri Çizelge 2' de verilmiştir. 
Çizelge1. Deneme alanına ait sıcaklık ve yağış verileri (Anonim, 2014b)

\begin{tabular}{|c|c|c|c|c|}
\hline \multirow{2}{*}{ Aylar } & \multicolumn{2}{|c|}{ Sicaklık, ${ }^{\circ} \mathrm{C}$} & \multicolumn{2}{|c|}{ Yağış, mm } \\
\hline & 2012-2013 y1l1 & 59 y1l ortalaması* & 2012-2013 y1l1 & 59 y1l ortalamas1* \\
\hline 2012 Ekim & 11 & 10.8 & 33.4 & 32.6 \\
\hline 2012 Kasim & 4.7 & 4.7 & 91.0 & 40.4 \\
\hline 2012 Aralık & 0 & -0.4 & 116.8 & 45.7 \\
\hline 2013 Ocak & -4.3 & -3.3 & 53.0 & 42.3 \\
\hline 2013 Şubat & -1.1 & -2 & 24.1 & 39.5 \\
\hline 2013 Mart & 4.1 & 3.1 & 38.2 & 45.6 \\
\hline 2013 Nisan & 9.8 & 9.1 & 59.8 & 60.4 \\
\hline 2013 Mayıs & 13.4 & 13.6 & 63.3 & 59.3 \\
\hline 2013 Haziran & 19.8 & 17.2 & 13.5 & 34.6 \\
\hline 2013 Temmuz & 21.4 & 20.2 & 0.4 & 8.6 \\
\hline 2013 Ağustos & 23.3 & 20.1 & 0 & 5.8 \\
\hline
\end{tabular}

*59 yıllık meteorolojik değer ortalamaları (1954-2013)

Çizelge 2. Çalışma başlangıcındaki bazı toprak özellikleri (Bulut ve Altuntaş, 2014; Bulut, 2015)

\begin{tabular}{lcc}
\hline \multirow{2}{*}{ Toprak Özellikleri } & \multicolumn{2}{c}{ Derinlik } \\
\cline { 2 - 3 } & $0-15 \mathrm{~cm}$ & $15-30 \mathrm{~cm}$ \\
\hline Tekstür sınıfi & \multicolumn{2}{c}{ 32 kil, \% 38 silt, \% 30 kum } \\
Nem içeriği (\%) & 11.42 & 16.54 \\
Hacim ağırlı̆̆ $\left(\mathrm{g} \mathrm{cm}^{-3}\right)$ & 1.37 & 1.44 \\
Penetrasyon direnci $(\mathrm{MPa})$ & 1.32 & 2.48 \\
pH & 8.27 & 8.31 \\
Toplam tuz (\%) & 0.02 & 0.02 \\
Kireç (\%) & 15.61 & 15.58 \\
Organik madde $(\%)$ & 1.69 & 1.74 \\
Toplam azot $(\%)$ & 0.08 & 0.09 \\
Yarayışlı fosfor $\left(\mathrm{P}_{2} \mathrm{O}_{5}, \mathrm{~kg} \mathrm{da}^{-1}\right)$ & 5.3 & 3.74 \\
Yarayşlı potasyum $\left(\mathrm{K}_{2} \mathrm{O}, \mathrm{kg} \mathrm{da}^{-1}\right)$ & 68.14 & 69.69 \\
\hline
\end{tabular}

Çalışmalar tesadüf blokları faktöriyel deneme desenine göre, 4 tekrarlı olarak her biri $500 \mathrm{~m}^{2}$ olan 16 parselde yürütülmüştür. Denemelerde 4 farklı toprak işleme sistemi uygulanmıştır. Bunlar; 1) Doğrudan ekim (DE) ( Doğrudan ekim makinesi), 2) Koruyucu toprak işleme (KT) (Çizel+diskli tırmık+hububat ekim makinesi), 3) Azaltılmış toprak işleme (AT) (Rotovatör+hububat ekim makinesi) ve 4) Geleneksel toprak işleme (GT) (Kulaklı pulluk+diskli tırmık+hububat ekim makinesi)'dir. Denemelerde gücü 90 BG olan Renault Cergos 350 4WD traktör kullanılmıştır. Denemelerde kullanılan alet makineler ve teknik özellikleri, Çizelge 3' de verilmiştir.
Çalışmada ekim işlemi, $20 \mathrm{~kg} \mathrm{da}^{-1}$ ekim normunda ve $50 \mathrm{~mm}$ ekim derinliğinde yapılmıştır. Ekim makineleri için ilerleme hızları makinelerin 100 metre mesafeyi katetme süreleri kronometre yardımı ile ölçülerek $5.5 \mathrm{~km}$ $\mathrm{h}^{-1}$ olarak belirlenmiştir (Bulut, 2015). Çalışmada kullanılan diğer alet ve makineler için ilerleme hızı değerleri, ASAE 1999 ve ASAE 2011 standartlarından ortalama olarak seçilmiştir. Çalışmada Bezostaja-1 kışlık buğday çeşidi kullanılmıştır. Ekimle birlikte dekara $6 \mathrm{~kg}$ saf $\mathrm{P}_{2} \mathrm{O}_{5}$ hesaplama yapılarak DAP gübresi, azotun kalan kısmı ilkbaharda ÜRE formunda $6 \mathrm{~kg} \mathrm{da}^{-1}$, a tamamlanacak şekilde uygulanmıştır. Üretim sezonu boyunca ilaçlama ve sulama yapılmamıştır (Bulut, 2015).

Çizelge 3. Çalışmada kullanılan makinelerin bazı özellikleri

\begin{tabular}{|c|c|c|c|c|c|c|}
\hline Makine & Ünite say1s1 & $\begin{array}{l}\text { Genişlik } \\
\text { (cm) }\end{array}$ & $\begin{array}{l}\text { Derinlik* } \\
\quad(\mathrm{cm})\end{array}$ & $\begin{array}{c}\text { A ğırlık } \\
(\mathrm{kg})\end{array}$ & $\begin{array}{c}\text { Tarla } \\
\text { etkinliğ } i_{* *}\end{array}$ & $\begin{array}{c}\text { Ekonomik } \\
\text { Ömür** (h) }\end{array}$ \\
\hline Traktör & - & - & - & 4130 & & 12000 \\
\hline Kulaklı pulluk & 5 Gövde & 130 & 25 & 628 & 0.85 & 2000 \\
\hline Çizel & 9 Ayak & 250 & 22 & 450 & 0.85 & 2000 \\
\hline Rotovatör & 48 L-şekilli bıçak & 199 & 13 & 600 & 0.85 & 2000 \\
\hline Diskli tırmık & 20 Disk & 180 & 10 & 520 & 0.80 & 2000 \\
\hline $\begin{array}{l}\text { Santrifüj gübre dağıtma } \\
\text { makinesi }\end{array}$ & Tek diskli & 225 & - & 220 & & 1200 \\
\hline Hububat ekim makinesi & 22 adet ekici ayak & 308 & 5 & 1200 & 0.70 & 1500 \\
\hline Doğrudan ekim makinesi & 15 adet ekici ayak & 210 & 5 & 2050 & 0.70 & 1200 \\
\hline Biçerdöver & - & 4570 & - & 8720 & - & 3000 \\
\hline
\end{tabular}

\footnotetext{
* Denemede uygulanan değerler. ** ASAE (2011)
} 
Toprak işleme ve ekim makinelerinin yakıt tüketimi değerleri aşağıdaki eşitlikler kullanılarak hesaplanmıştır (ASAE, 1999; ASAE, 2011; Heller et al., 2003). Santrifüj gübre dağıtma makinesi ve biçerdöverin yakıt tüketimi değerleri Özden ve Soğancı (1996)'dan alınmıştır. Yağ tüketimi değerleri ise yakıt tüketiminin \% 4.5 'i olacak şekilde hesap edilmiştir (Özcan, 1985; Alpkent, 1984).

$\mathrm{Di}=\mathrm{Fi}(\mathrm{A}+\mathrm{B} \mathrm{S}+\mathrm{C} \mathrm{S} 2) \mathrm{W} \mathrm{T}$

$\mathrm{PT}=(\mathrm{Di} \mathrm{S}) / 3.6 \mathrm{Em} \mathrm{Et}$

Qdiesel $=\mathrm{PT}(2.64(\mathrm{PT} / \mathrm{PT} \max )+3.91-0.203 \sqrt{ } 738$

$\left.\left(\mathrm{P}_{\mathrm{T}} / \mathrm{P}_{\mathrm{T} \max }\right)+173\right)$

$\mathrm{Ca}=(\mathrm{S} \mathrm{W} \mathrm{Ef}) / 10$
Eşitliklerde; $D_{i}=$ çeki kuvveti $(\mathrm{N}) ; F_{i}=$ toprak tekstürüne bağlı boyutsuz bir faktör; $\mathrm{A}, \mathrm{B}$, ve $\mathrm{C}=$ makineye özgü parametreler; $\mathrm{S}=$ çalışma hızı $\left(\mathrm{km} \mathrm{h}^{-1}\right) ; \mathrm{W}$ $=$ makine iş genişliği $(\mathrm{m}) ; \mathrm{T}=$ makine iş derinliği $(\mathrm{cm})$; $\mathrm{E}_{\mathrm{m}}=$ transmisyon ve güç aktarma organlarının mekanik etkinliğ $\mathrm{i}=0,96$ (dişli transmisyon sistemine sahip traktör için); $\mathrm{E}_{\mathrm{t}}=$ çeki etkinliği; $\mathrm{Q}_{\text {dizel }}=$ yakıt tüketimi $\left(\mathrm{l} \mathrm{h}^{-1}\right) ; \mathrm{P}_{\mathrm{T}}$ $=$ işlem için toplam iş gereksinimi $(\mathrm{kW}) ; \mathrm{P}_{\mathrm{Tmax}}=$ maksimum elde edilen PTO gücü $(\mathrm{kW}) ; \mathrm{C}_{\mathrm{a}}=$ tarla kapasitesi $\left(h^{-1} h^{-1}\right) ; E_{f}=$ tarla etkinliğidir. Saatlik yakıt tüketimi değeri (Eşitlik 3) ile tarla kapasitesi (Eşitlik 4) değeri çarpılarak birim alandaki yakıt tüketimi $\left(1 \mathrm{ha}^{-1}\right)$ bulunmuştur. Eşitliklerde verilen parametrelere ait sayısal değerler çalışmada kullanılan her bir alet ve makine için Çizelge 4' te verilmiştir.

Çizelge 4. Yakıt tüketiminin hesaplanmasında kullanılan makinelerle ilgili parametrelere ait sayısal değerler (ASAE, 1999; ASAE, 2011)

\begin{tabular}{lllllll}
\hline & $\mathrm{A}$ & $\mathrm{B}$ & $\mathrm{C}$ & $\mathrm{F}_{\mathrm{i}}$ & $\mathrm{E}_{\mathrm{t}}$ & $\mathrm{E}_{\mathrm{f}}$ \\
\hline Kulaklı pulluk & 652.00 & 0.00 & 5.10 & 0.70 & 0.77 & 0.85 \\
Çizel & 91.00 & 5.40 & 0.00 & 0.85 & 0.77 & 0.85 \\
Rotovatör & 600.00 & 0.00 & 0.00 & 1.00 & 0.77 & 0.85 \\
Diskli tırmık & 216.00 & 11.20 & 0.00 & 0.88 & 0.75 & 0.80 \\
Hububat ekim makinesi & 300.00 & 0.00 & 0.00 & 1.00 & 0.75 & 0.70 \\
Doğrudan ekim makinesi & 720.00 & 0.00 & 0.00 & 0.79 & 0.77 & 0.70 \\
\hline
\end{tabular}

Buğday üretiminde kullanılan girdiler ve çıtıtların enerji karşılıklarının belirlenmesi ve üretimin enerji analizlerinin yapılabilmesi için Cizelge $5^{\prime}$ te verilen enerji eş değerleri kullanılmıştır. Girdi ve çıktı değerleri, enerji eşdeğerleri ile çarpılarak enerji miktarı elde edilmiştir. Traktör ve makine imalat enerjisi ise traktör ve makine ağırlığ $1(\mathrm{~kg})$ ile traktör ve makine imalat enerjisi eşdeğerinin çarpım değeri $\left(\mathrm{MJ} \mathrm{ha}^{-1}\right)$, traktör veya makinenin ekonomik ömrü (h) ile traktör veya makinenin efektif tarla kapasitesinin $\left(\right.$ ha $\mathrm{h}^{-1}$ ) çarpım değerine oranlanarak hesap edilmiştir

Üretimde girdi kaynaklarının ne kadar verimli kullanıldığı ve ne kadar etkin bir şekilde çıktıya dönüştüğünü gösteren; enerji oranı, özgül enerji değeri, enerji üretkenliği değeri, net enerji verimi ve enerji kârlılığı aşağıda verilen eşitlikler kullanılarak hesaplanmıştır (Erdoğan, 2009; Şehri, 2012).

Çizelge 5. Buğday üretimindeki girdi ve çıktıların enerji eşdeğerleri

\begin{tabular}{|c|c|c|}
\hline Girdi ve Çıktı (birim) & Enerji Eşdeğeri $\quad\left(\mathrm{MJ}\right.$ birim $\left.^{-1}\right)$ & Kaynak \\
\hline \multicolumn{3}{|l|}{ GİRDİ } \\
\hline İnsan iş gücü (h) & 2.3 & Kizilaslan (2009) \\
\hline Tarım makinesi & 121.3 & Doering (1980) \\
\hline Traktör & 158.3 & Doering (1980) \\
\hline Azotlu gübre $(\mathrm{kg})$ & 60.6 & Bojaca ve Schrevens (2010) \\
\hline Fosforlu gübre $(\mathrm{kg})$ & 11.10 & Bojaca ve Schrevens (2010) \\
\hline Diesel yakıt (l) & 47.8 & Hetz (1992) \\
\hline Yağ (l) & 42.5 & Hetz (1992) \\
\hline Tohum $(\mathrm{kg})$ & 15 & Öztürk (2011) \\
\hline \multicolumn{3}{|l|}{ ÇIKTI } \\
\hline Ürün $(\mathrm{kg})$ & 14.7 & Mani ve ark. (2007) \\
\hline
\end{tabular}


Enerji Oranı= Enerji çıktısı $\left(\mathrm{MJ} \mathrm{ha}^{-1}\right) /$ Enerji girdisi $\left(\mathrm{MJ} \mathrm{ha}^{-1}\right)$

Özgül enerji $\left(\mathrm{MJ} \mathrm{kg}^{-1}\right)=$ Enerji girdisi $\left(\mathrm{MJ} \mathrm{ha}^{-1}\right) / \operatorname{Verim}\left(\mathrm{kg} \mathrm{ha}^{-1}\right)$

Enerji verimliliği $\left(\mathrm{kg} \mathrm{MJ}^{-1}\right)=\operatorname{Verim}\left(\mathrm{kg} \mathrm{ha}^{-1}\right) /$ Enerji girdisi $\left(\mathrm{MJ} \mathrm{ha}^{-1}\right)$

Net enerji $\left(\mathrm{MJ} \mathrm{ha}^{-1}\right)=$ Enerji girdisi $\left(\mathrm{MJ} \mathrm{ha}^{-1}\right)$ - Enerji çıktısı $\left(\mathrm{MJ} \mathrm{ha}^{-1}\right)$

Enerji karlılığ $1=$ Net enerji $\left(\mathrm{MJ} \mathrm{ha}^{-1}\right) /$ Enerji girdisi $\left(\mathrm{MJ} \mathrm{ha}^{-1}\right)$

Buğday üretiminde enerji kullanımı bakımından toprak işleme sistemleri arasındaki farklılı̆̆ koyabilmek için, elde edilen değerler SPSS 17 istatistik paket programı kullanılarak varyans analizi ve çoklu karşılaştırma testine (LSD) tabi tutulmuştur.

\section{Bulgular ve Tartışma}

Çalışmada kullanılan toprak işleme sistemleri, buğday verimini istatistiksel olarak $\mathrm{P}<0.01$ seviyesinde önemli bir şekilde etkilemektedir. En yüksek buğday verimi geleneksel toprak işlemede (3 $300 \mathrm{~kg} \mathrm{ha}^{-1}$ ) ve en düşük buğday verimi ise doğrudan ekim sisteminde (2 $930 \mathrm{~kg} \mathrm{ha}^{-1}$ ) elde edilmiştir. İstatistiksel olarak GT-AT, AT-KT ve KT-DE sistemleri arasında önemli bir farklılık bulunmamaktadır (Çizelge 6) (Bulut, 2015).

Toprak işleme sistemlerinin uygulandığı parsellerde hasada kadar uygulanan tüm işlemlerdeki yakıt tüketimi ve çalışma süresi değerleri, Çizelge 7'de verilmiştir.
Toprak işleme sistemleri, yakıt tüketimleri bakımından $\mathrm{GT}>\mathrm{AT}>\mathrm{KT}>\mathrm{DE}$ şeklinde sıralanmıştır. Kullanılan makineler arasında, kulaklı pulluk yakıt tüketimi en yüksek olan makinedir. Geleneksel toprak işleme ile karşılaştırıldığında AT, KT ve DE sistemlerindeki yakıt tüketimi sirasıyla \% 46.95, \% 47.04 ve \% 77.88 daha azdır (Çizelge 7).

Çizelge 6. Toprak işleme sistemlerindeki buğday verim değerleri (Bulut ve Altuntaş, 2014; Bulut, 2015).

\begin{tabular}{lc}
\hline Toprak İşleme Sistemleri & Verim $\left(\mathrm{kg} \mathrm{ha}^{-1}\right)^{*}$ \\
\hline (DE) Doğrudan Ekim & $2930 \mathrm{c}$ \\
(KT) Çizel + Diskli tırmık + Ekim & $3135 \mathrm{bc}$ \\
(AT) Freze + Ekim & $3222 \mathrm{ab}$ \\
(GT) Kulaklı Pulluk + Diskli & \\
Tırmık + Ekim & $3300 \mathrm{a}$ \\
\hline
\end{tabular}

*Sütunda aynı harfle gösterilen uygulamalar arasında istatistiksel olarak fark yoktur.

Çizelge 7. Toprak işleme sistemlerinin ortalama yakıt tüketimi değerleri

\begin{tabular}{lcc}
\hline Toprak işleme Sistemleri & Yakıt Tüketimi $\left(1\right.$ ha $\left.^{-1}\right)$ & ${\text { Tarla Kapasitesi }\left(\mathrm{h} \mathrm{ha}^{-1}\right)}^{\text {(DE) Doğrudan Ekim }}$ \\
(KT) Koruyucu Toprak İşleme & 9.97 & 3.18 \\
(AT) Azaltılmış Toprak İşleme & 23.87 & 4.54 \\
(GT) Geleneksel Toprak İşleme & 25.26 & 4.44 \\
\hline
\end{tabular}

Çalışmada, buğday üretimi için gereksinim duyulan girdiler içerisinde incelenen dört toprak işleme sisteminde en yüksek payın gübre enerjisinde olduğu ve bunu tohum, yakıt+yağ ve makine imalat enerjisinin takip ettiği belirlenmiştir. Toprak işleme sistemleri, toplam enerji girdisi bakımından GT $>$ AT $>\mathrm{KT}>\mathrm{DE}$ şeklinde sıralanmıştır. Toprak işleme sistemlerinin enerji girdilerinde farklılık oluşturan girdi yakıt+yağ, makine imalat ve insan iş gücü enerjisi girdisidir. Yakıt+yağ enerjisi girdisi DE sisteminde toplam enerji girdisinin \% 11.49'unu oluştururken, KT, AT ve GT sistemlerinde sirasiyla $\% \quad 17.92, \quad \% \quad 18.58$ ve $\% \quad 25.58$ 'ini oluşturmaktadır (Çizelge 8). Benzer şekilde Adana'da yapılan bir çalışmada buğday üretiminin hem düze ekim, hem de sırta ekim yönteminde toplam enerji girdileri içerisinde en büyük oranın gübre enerjisi girdisinin olduğu, bunu sırasıyla tohum enerjisi girdisi ve yakıt yağ enerjisi girdisinin takip ettiği görülmüştür (Karaağaç ve ark. 2012).

Çizelge 8. Buğday üretimi için toprak işleme sistemlerinin toplam enerji eşdeğerleri (MJ ha-1)

\begin{tabular}{|c|c|c|c|c|}
\hline \multirow{2}{*}{ Girdiler ve Çıktı } & \multicolumn{4}{|c|}{ Toprak işleme sistemleri } \\
\hline & $\mathrm{DE}$ & KT & $\mathrm{AT}$ & GT \\
\hline \multicolumn{5}{|l|}{ A. Girdiler } \\
\hline 1. İnsan iş gücü & $7.30(0.08)$ & $10.44(0.11)$ & $10.21(0.10)$ & $12.06(0.11)$ \\
\hline 2. Makine imalat & $664.87(7.38)$ & $591.22(6.14)$ & $612.73(6.29)$ & $662.79(6.18)$ \\
\hline 3. Yakıt+Yăg & $1035.25(11.49)$ & $1726.03(17.92)$ & $1809.03(18.58)$ & $2741.71(25.58)$ \\
\hline 4. Gübre & $4302.00(47.75)$ & $4302.00(44.67)$ & $4302.00(44.20)$ & $4302.00(40.14)$ \\
\hline 5. Tohum & $3000.00(33.30)$ & $3000.00(31.15)$ & $3000.00(30.82)$ & $3000.00(27.99)$ \\
\hline Toplam Girdi & $9009.42(100)$ & $9629.69(100)$ & $9733.97(100)$ & $10718.57(100)$ \\
\hline \multicolumn{5}{|l|}{ B. Çıktı } \\
\hline Buğday & 43071.00 & 46084.50 & 47370.75 & 48510.00 \\
\hline
\end{tabular}


Ghorbani ve ark. (2011), sulamanın yapıldı̆̆ 1 ve yapılmadığ 1 şartlarda buğday üretiminde toplam enerji ihtiyacının sirasiyla $45367 \mathrm{MJ}^{-1}$ ve $9354 \mathrm{MJ} \mathrm{ha}^{-1}$, Gökdoğan ve Sevim (2016) buğday üretiminde enerji girdisinin $25876.29 \mathrm{MJ} \mathrm{ha}^{-1}$, Karaağaç ve ark. (2012) buğday üretiminde enerji girdisinin düze ekim de $18392.10 \mathrm{MJ} \mathrm{ha}^{-1}$ ve sirta ekim de $18494.01 \mathrm{MJ} \mathrm{ha}^{-1}$ olduğunu ifade etmişlerdir. Çalışmada, enerji çıktısı değerleri incelendiğinde, verim değerlerinde olduğu gibi en yüksek çıktı enerjisi GT sisteminde ve en düşük enerji çıktısı ise AE sisteminde elde edilmiştir (Çizelge 8).

Buğday üretimde girdi kaynaklarının ne kadar verimli kullanıldığı ve ne kadar etkin bir şekilde çıktıya dönüştüğünü ifade edebilmek için toprak işleme sistemlerinin Çizelge 9' da verilen enerji parametrelerine göre karşılaştırılması gerekir. Varyans analizi sonuçları toprak işleme sistemlerinin enerji parametreleri üzerine istatistiksel olarak $\mathrm{P}<0.01$ seviyesinde önemli bir etkisinin olduğunu göstermiştir. Toprak işleme sistemleri arasındaki farklılığı görmek için yapılan çoklu karşılaştırma testi sonuçları ve ortalama değerler Çizelge 9' da verilmiştir. En yüksek enerji oranı AT ve en düşük enerji oranı ise GT sisteminde elde edilmiştir. Geleneksel toprak işleme sisteminde her ne kadar verim en yüksek değerde olsa da, enerji girdisinin yüksek olması enerji oranının diğer sistemlere göre daha düşük olmasına neden olmuştur. DE uygulamasında ise verim düşük olmasına rağmen, enerji girdisinin de düşük olması oranın yükselmesini sağlamıştır. Ghorbani ve ark. (2011) İran' da kuru tarım şartlarında buğday üretiminde enerji oranının 3.38 ve sulamanın yapıldığı şartlarda ise 1.44 olduğunu belirtmişlerdir.

Çizelge 9. Buğday üretiminde toprak işleme sistemlerinin enerji analizi

\begin{tabular}{lllll}
\hline \multirow{2}{*}{ Enerji Parametreleri } & \multicolumn{3}{c}{ Toprak İşleme Sistemleri } \\
\cline { 2 - 5 } & $\mathrm{DE}$ & $\mathrm{KT}$ & $\mathrm{AT}$ & $\mathrm{GT}$ \\
\hline Enerji Oranı & $4.78 \mathrm{a}$ & $4.79 \mathrm{a}$ & $4.87 \mathrm{a}$ & $4.53 \mathrm{~b}$ \\
Özgül Enerji $\left(\mathrm{MJ} \mathrm{kg}^{-1}\right)$ & $3.07 \mathrm{a}$ & $3.07 \mathrm{a}$ & $3.02 \mathrm{a}$ & $3.25 \mathrm{~b}$ \\
Enerji Verimliliğ $\left(\mathrm{kg} \mathrm{MJ}^{-1}\right)$ & $0.33 \mathrm{a}$ & $0.33 \mathrm{a}$ & $0.33 \mathrm{a}$ & $0.31 \mathrm{~b}$ \\
Net Enerji $\left(\mathrm{MJ} \mathrm{ha}^{-1}\right)$ & $34061.58 \mathrm{~b}$ & $36454.81 \mathrm{a}$ & $37636.78 \mathrm{a}$ & $37791.43 \mathrm{a}$ \\
Enerji Kârlılı̆̆ & $3.78 \mathrm{a}$ & $3.79 \mathrm{a}$ & $3.87 \mathrm{a}$ & $3.53 \mathrm{~b}$ \\
\hline
\end{tabular}

Çalışmada, toprak işleme sistemleri enerji oranı yönünden de $\mathrm{AT}>\mathrm{KT}>\mathrm{DE}>\mathrm{GT}$ şeklinde sıralanmaktadır. AT ve GT sistemlerinde $1 \mathrm{~kg}$ buğday üretebilmek için enerji gereksinimi sirasiyla $3.02 \mathrm{MJ}$ ve $3.25 \mathrm{MJ}$ iken KT ve DE sistemlerinde 3.07 MJ ile 3.07 MJ enerjiye gereksinim duyulmaktadır (Çizelge 8). Karaağaç ve ark. (2012), 1 kg buğdayın üretilmesi için gerekli olan enerji değerinin düze ekim yönteminde $2.08 \mathrm{MJ}$ iken, sirta ekim yönteminde 2.61 MJ, Gökdoğan ve Sevim (2016) 4.95 MJ, Özpınar ve Ürkmez (2011) 6.20 MJ olduğunu belirtmektedir.

Çalışmadaki sonuçlara göre, GT sisteminde, 1 MJ enerji ile $0.31 \mathrm{~kg}$ buğday üretiliyorken, bu değer AT, KT ve $\mathrm{DE}$ sistemlerinde ise $0.33 \mathrm{~kg}$ olarak belirlenmiştir. Ayrıca enerji kârlılığının da GT sisteminde en düşük olduğu belirlenmiştir (Çizelge 9).

Sistemlerin net enerji değerleri incelendiğinde; GT sisteminde $37791.43 \mathrm{MJ} \mathrm{ha}^{-1}$ ile en yüksek, DE sisteminde ise $34061.58 \mathrm{MJ} \mathrm{ha}^{-1}$ ile en düşük değerin elde edildiği görülmektedir. Çoklu karşılaştırma testi sonuçlarına göre; net enerji kazancı dışındaki enerji parametrelerinde DE, KT ve AT sistemleri arasında istatistiksel olarak önemli bir farklılık yoktur. Net enerji kazancinda ise, KT, AT ve GT sistemleri istatistiksel olarak aynı grupta yer almaktadır. Net enerji kazancı dikkate alındığında bölgede buğday tarımında geleneksel toprak işleme tercih edilmelidir. Ancak, diğer enerji parametreleri dikkate alındığında istatistiksel sonuçlar çalışma bölgesinde, kuru tarım şartlarında enerji kullanımı açısından geleneksel toprak işleme yerine doğrudan ekim, koruyucu toprak işleme veya azaltılmış toprak işleme sistemlerinden birisinin kullanılması gerektiğini göstermektedir. Çarman ve ark. (2014)' da yaptıkları çalışmada önerilerini enerji oranını dikkate alarak yapmışlar ve buğday ve nohut üretiminde en yüksek enerji oranına sahip olan herbisit+doğrudan ekim uygulamasını tavsiye etmişlerdir. Buğday tarımında enerji etkinliğinin belirlenmesi ile ilgili olarak yapılan çalışmalar (Tabatabaeefar ve ark., 2009; Ghorbani ve ark., 2011; Özpınar ve Ürkmez, 2011; Çarman ve ark., 2014; Golaszewski ve ark., 2014; Karaağaç ve ark., 2012; Gökdoğan ve Sevim, 2016; Yıldız, 2016) incelendiğinde iklim, toprak özellikleri ve uygulanan yöntemler gibi faktörlere bağlı olarak enerji parametrelerinin değiştiği görülmektedir. $\mathrm{Bu}$ sonuçlar, sürdürülebilir tarımsal üretim için farklı coğrafi alanlar ve iklim bölgelerinde bitkisel üretim için uygun amenajmanların belirlenmesinin önemini ortaya koymaktadır.

\section{Sonuç}

Bu çalışmada, sürdürülebilir tarım çerçevesinde kuru şartlarda buğday tarımında toprak işleme sistemleri enerji kullanım etkinliği yönünden karşılaştırılmıştır. $\mathrm{Bu}$ amaçla; her bir toprak işleme sistemi için enerji girdisi, enerji çıktısı ve enerji parametreleri belirlenmiştir. En yüksek enerji girdisi ve enerji çıktısı geleneksel toprak işlemede en düşük girdi ve çıktı değerleri ise doğrudan ekim sisteminde elde edilmiştir. Toplam girdi içerisinde en yüksek payı sırasıyla gübre, tohum ve yakıt+yağ 
enerjisi almıştır. Kullanılan toprak işleme sistemlerinin enerji parametrelerini istatistiksel olarak önemli bir şekilde etkilediği belirlenmiştir. Enerji oran1, özgül enerji, enerji verimliliği ve enerji kârlılığı değerlerine göre en iyi sonucu veren azaltılmış toprak işleme olmuştur. Bunun yanında; doğrudan ekim, koruyucu toprak işleme ve azaltılmış toprak işleme sistemi arasında istatistiksel olarak önemli bir farklılık olmadığından bölgede buğday tarımında geleneksel yöntem yerine etkin enerji kullanımı açısından bu yöntemlerin kullanılması gerektiği sonucuna varılmıştır.

\section{Kaynaklar}

Alikhani, M.A., Nezhad, R.K., 2004. Energy efficiency of 1rrigated wheat production in traditional and mechanized systems at East Azarbayjan Province, Iran. Proceedings of The Fourth International Iran \& Russia Conference, 675-681.

Alpkent, N., 1984. Tarımda enerji kullanımı ve enerji tasarrufu. Milli Prodüktivite Merkezi Yayınları No: 296. Ankara.

Anonim, 2014a. Sivas il gelişme planı, Sivas.

Anonim, 2014b. Sivas ili y1llık toplam yağıș verileri, http://www.mgm.gov.Tr/veridegerlendirme/yilliktoplamyagisverileri.aspx?m=sivas, (03.09.2014).

ASAE, 1999. ASAE Standarts. D497.4 MAR99: Agricultural machinery data. pp. 350-357 ASAE 2950 Niles Rd., St. Joseph, MI, 49085-9659, USA.

ASAE, 2011. ASAE Standarts. D497.7 MAR2011 (R2015): Agricultural machinery data. pp. 1-14 ASABE 2950 Niles Rd., St. Joseph, MI, 49085-9659, USA.

Bojaca, C.R., Schrevens, E., 2010. Energy assessment of peri-urban horticulture and its uncertainty: Case Study for Bogota, Colombia. Energy, 35(5): 21092118.

Bonari, E., Mazzoneini, M., Peruzzi, A., 1995. Effects of conventional and minimum tillage on winter oil seed rape. Soil Tillage and Research, 33(2): 91-108.

Borin, M., Merini, C., Sartori, L., 1997. Effects of tillage systems on energy and carbon balance in northeastern Italy. Soil Tillage and Research, 40(3): 209226.

Bulut, O.N., Altuntaş, E., 2014. Sivas yöresinde buğday tarımında farklı toprak işleme yöntemlerinin toprak fiziksel özellikleri, bitki gelişimi ve ürün verimi üzerine etkisi. Gaziosmanpaşa Üniversitesi Ziraat Fakültesi Dergisi, 32(3): 39-51.

Bulut, O.N., 2015. Buğday tarımında farklı toprak işleme yöntemlerinin toprak özellikleri, tarla filiz çıkışı ve verim üzerine etkileri. Yüksek Lisans Tezi Gaziosmanpaşa Üniversitesi Fen Bilimleri Enstitüsü, Biyosistem Mühendisliği Anabilim Dalı, $88 \mathrm{~s}$, Tokat.

Chaplin, J., Jenane, C., Lueders, M., 1988. Drawbar energy use for tillage operations on loamy sand. Transaction of The ASAE, 31(6):1692-1694.

Çarman, K., Uyanöz, R., Marakoğlu, T., Kirtiş, F., 2014. Alternatif toprak işleme sistemlerinin 3E (Enerji, erozyon, emisyon) üzerine etkileri. TÜBİTAK $111 \mathrm{O}$ 182 nolu Proje Sonuç Raporu.

Doering, O.C., 1980. Accounting for energy in farm machinery and buildings. In: Pimentel David, editor. Handbook of Energy Utilization in Agriculture. FL, USA: CRC Press, Inc, ISBN 0-8493-2661-3: 9-14.

Erdoğan, Y., 2009. Tarımsal üretimde enerji girdi çıktı analizlerinde kullanılacak internet tabanlı bir yazılımın geliştirilmesi. Çukurova Üniversitesi Fen Bilimleri Enstitüsü Tarım Makineleri Anabilim Dalı, Adana.

Ghorbani, R., Mondani, F., Amirmoradi, S., Feizi, H., Khorramdel, S., Teimouri, M., 2011. A case study of energy use and economical analysis of irrigated and dryland wheat production systems. Applied Energy, 88: 283-288.

Gołaszewski, J., van der Voort, M., Meyer-Aurich, A., Baptista, F., Balafoutis, A., Mikkola, H.J., 2014. Comparative analysis of energy efficiency in wheat production in different climate conditions of Europe. Journal of Agricultural Science and Technology B, 4, 632-640.

Gökdoğan, O., Sevim, B., 2016. Determination of Energy Balance of Wheat Production in Turkey: A Case Study of Eskil District of Aksaray Province. Tekirdağ Ziraat Fakültesi Dergisi, 13(4): 36-43.

Gözübüyük Z., Çelik A., Öztürk İ., Demir O., Adıgüzel, MC., 2012. Buğday üretiminde farklı, toprak işlemeekim sistemlerinin enerji kullanım etkinliği yönünden karşılaştırılması. Tarım Makineleri Bilimi Dergisi, 8(1): 25-34.

Hatirli, S. A., Ozkan, B., Fert, C., 2006. Energy inputs and crop yield relationship in greenhouse tomato production. Renewable Energy, 31: 427-438.

Heller M.C, Keoleian G.A, Volk T.A., 2003. Life cycle assessment o a willow bioenergy cropping system. Biomass and Bioenergy, 25: 147-165.

Hetz E.J., 1992. Energy utilization in Chilean agriculture, Agricultural Mechanization in Asia. Africa And Latin America, 23: 52-56.

Karaağaç, H.A., Aykanat, S., Coşkun, M.A., Şimşek, M., 2012. Buğday tarımında farklı ekim tekniklerinin enerji bilançosu. 27. Tarımsal Mekanizasyon Ulusal Kongresi, 5-7 Eylül 2012, Bildiriler Kitabı, 169-173.

Kizilaslan, H., 2009. Input and output energy analysis of cherries production in Tokat province of Turkey. Applied Energy, 86: 1354-1358.

Kosutic. S., Filipovic, D., Gospodaric, Z., Husnjak, S., Kovacev, I., Copec, K., 2005. Effects of different soil tillage systems on yields of maize, winter wheat and soybean on albic luvisol in north-west Slavonia. J. Central Eur. Agric., 6: 241-248.

Mani, I., P. Kumar, J. S. Panwar, Kant, K., 2007. Variation in energy consumption in production of wheat-maize with varying altitudes in hill regions of Himachal Prades, India. Energy 32, 2336-2339.

Marakoglu, T., Çarman K., 2010. Energy balance of direct seeding applications used in wheat production 
in Middle Anatolia. African Journal of Agricultural Research, 5(10), 988-992.

Mohammadi, A., Omid, M., 2010. Economical analysis and relation between energy inputs and yield of greenhouse cucumber production in Iran. Applied Energy, 87, 191-196.

Mousavi Avval, S.H., Rafiee, S., Keyhani, A., 2012. Energy efficiency analysis in agricultural productions: parametric and non-parametric approaches, energy efficiency - a bridge to low carbon economy, Dr. Zoran Morvaj (Ed.), ISBN: 978953-51-0340-0, InTech.

Özcan M.T., 1985. Mercimek hasat ve harman yöntemlerinin iş verimi kalitesi. enerji tüketimi ve maliyet yönünden karşılaştırılması ve uygun bir hasat makinas1 geliştirilmesi üzerine araştırmalar. Ç.Ü. Ziraat Fakültesi Tarımsal Mekanizasyon Bölümü. Adana.

Özden, M., Soğanc1, A., 1996. Türkiye tarım alet ve makinaları işletme değerleri rehberi. Köy Hizmetleri Genel Müdürlüğü A.P.K. Dairesi Başkanlığı Toprak ve Su Kaynakları Araştırma Şube Müdürlüğü Yayın No: 92, Ankara.

Özpınar, S., Ürkmez, Ü., 2011. Energy use pattern and economic analysis of wheat and maize production In West Turkey. 11th International Congress on Mechanization and Energy in Agriculture, 21-23 Eylül 2011, pp.145-151, İstanbul, Türkiye.

Öztürk, H. H., 2011. Bitkisel üretimde enerji yönetimi. Hasad yayınc1lı.
Pelizzi, G., Cavalchini, A., Lazzari, M., 1988. Energy in agricultural machinery and mechanization. London, New York: Elsevier Applied Sciences, ISBN-13: 978-94-010-7108-6.

Singh, G.; Singh, S., Singh, J., 2004. Optimization of energy inputs for wheat crop in Punjab. Energy Conversion and Management, 45: 453-465

Şehri, M., 2012. Adana yöresi pamuk üretiminde enerji kullanım etkinliği ve maliyet analizi. Yüksek Lisans Tezi. Çukurova Üniversitesi Fen Bilimleri Enstitüsü Tarım Makinaları Anabilim Dalı, Adana.

Tabatabaeefar, A., Emamzadeh, H., Ghasemi Varnamkhasti, M., Rahimizadeh, R., Karimi, M., 2009. Comparison of energy of tillage systems in wheat production. Energy, 34: 41-45.

TUIK, 2017. Türkiye İstatistik Kurumu (TUIK) Web sitesi. Bitkisel üretim istatistikleri.http://www.tuik.gov.tr/bitkiselapp/bi tkisel.zul. Erişim Tarihi: 05.09.2017

Uhlin, H., 1998. Why energy productivity is increasing: an $\mathrm{I}-\mathrm{O}$ analysis of Swedish agriculture. Agric Syst 56(4):443-465.

Y1ldiz, T., 2016. An input-output energy analysis of wheat production in Çarşamba district of Samsun province. Gaziosmanpaşa Üniversitesi Ziraat Fakültesi Dergisi, 33(3): 10-20. 